\title{
REGIONAL PLANNING OF URBAN SUSTAINABLE DEVELOPMENT IN THE BIG BAKU AREA
}

\author{
E.F. HUSEYNOV ${ }^{1} \&$ A.A. ALIYEV ${ }^{2}$ \\ ${ }^{1}$ Department of Architecture and Urban Planning, Azerbaijan Architecture and Construction University, Baku, Azerbaijan. \\ ${ }^{2}$ Municipalities of the Khyrdalan City, Apsheron Area, Azerbaijan.
}

\begin{abstract}
The regional planning of urban sustainable development in Big Baku was undertaken as part of the Baku Strategic Plan prepared by the Architecture and Urban Planning Department of Azerbaijan Architecture and Construction University and supported by the Society of Urbanists of Azerbaijan Research Group. The key purpose of the research was to provide useful information for developing planning and design strategies that will foster sustainable urbanisation through enhancing quality of life (QoL), which is one of the most important principles of sustainable urbanisation on Apsheron peninsula. Another purpose was to explore the impact of environmental, economic, social, physical and health-related indicators on QoL satisfaction among Big Baku settlements. Ultimately, the research will provide recommendations, which will further enhance the QoL in Baku at a number of levels, from empowering communities at a local level to participate in the evolution of their neighbourhoods to influencing institutional and corporate objectives and sustainability policies. The information collated will feed into the Baku Regional Planning Process and determines developed strategies for urban development. The study aims to improve the functional and physical structure of settlements by proposing an Urban Sustainable Development Model (USDM). An examination of the current design practice showed that there is a lack of systematic evaluation and revitalisation methods. Hence, the main objective of the proposed USDM is to evaluate existing settlement environments and requalify them with respect to an inclusive approach. The study concludes by highlighting the importance of USDM from two points of view: (1) importance of a systematic evaluation approach to effectively deal with the challenge of requalifying the settlement environments and (2) the designer's key role during the revitalisation process. In this paper, the methodology of the research and initial findings related to satisfaction with settlement and neighbourhood will be presented.
\end{abstract}

Keywords: Big Baku, development, environment, planning, regional, settlement, sustainable, urban.

\section{INTRODUCTION}

The Big Baku study for the regional planning of urban sustainable development was carried out by the Architecture and Urban Planning Department of Azerbaijan Architecture and Construction University, and supported by the Society of Urbanists of Azerbaijan Research Group as part of the preparation of Baku Strategic Regional Plan. The research concentrated on two aspects of planning urban sustainable development: Planning of the physical environment in the Big Baku areas [1] and quality of life (QoL) with respect to social and economic indicators and the satisfaction of the inhabitants $[2,3]$. The first part is directly used to demonstrate the problem areas in Big Baku with respect to the different characteristics of the physical environment. The second part is aimed to be used in comparing the satisfaction and perception of settlements in different environmental settings.

The preliminary results of the survey were used to broadly demonstrate the problem areas with respect to the various indicators. Consequently, neighbourhoods have been graded with respect to the indicators used in the study and it has been possible to demonstrate the macro and micro neighbourhoods (Fig. 1).

QoL is a concept that has inspired much research in the past decades and has established a strong position in local, national and European Union (EU) agenda [4]. The concept provides data crucial for informing community and neighbourhood policies and practices. The research into QoL in Baku, 


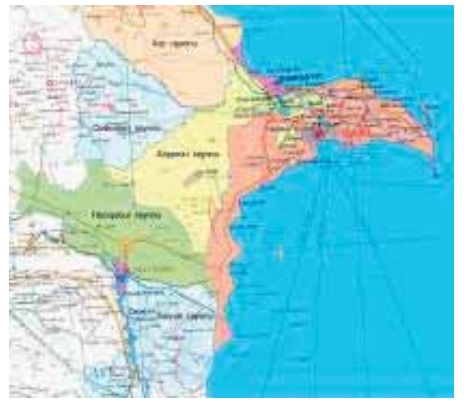

1. Big Baku area in territory of Azerbaijan

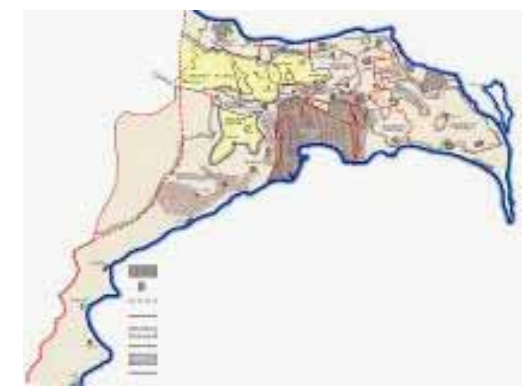

2. Capital Baku and other settlements in the Big Baku area

Figure 1: Territorial borders of Big Baku and its place among other administrative areas of Azerbaijan.

which 'engaged' respondents from communities and considers their perceptions of their QoL as an element of engagement conducive to the principles of the promotion of social cohesion as advocated by the EU. Thus, research into settlements and neighbouring areas through the QoL research provides a unique opportunity to measure community and neighbourhood satisfaction through evidence-based research to 'make the difference' to people's QoL by informing future neighbourhood and regeneration policy in Big Baku and encouraging framework conducive to citizen involvement.

\section{METHODOLOGY OF URBAN SUSTAINABLE DEVELOPMENT RESEARCH FOR REGIONAL PLANNING}

During the strategic regional planning process, the settlements and QoL group identified two research areas. They were the assessment of the physical quality of settlements in Big Baku. Information was collated via the physical questionnaire survey of neighbourhoods in Big Baku [1]. First, an assessment of the quality of community Life was carried out by measuring people's objective and subjective experiences of their living environment. The purpose of the research was to first feed the data into the strategic regional plan and then to determine the development strategy of the settlement areas in terms of both physical (objective) and perceptive (subjective) experiences. Second, to determine the spatial criteria for settlements. Information from both the physical and the QoL survey was then placed into a data set together with statistical information [5]. The first stage was to provide data on density and land value. Identification of the location of neighbourhood units was determined by existing legally defined borders as determined by the local municipalities (Fig. 2).

The research not only acknowledges that each settlement is unique in character but also recognises that there will be some similarities. Neighbourhoods were chosen that were representative of the whole city. In identifying the appropriate neighbourhoods, a formula for calculating density and land value was implemented.

The density of an area was calculated based on the size of population and neighbourhood areas by using the GIS in terms of population by ascertaining numbers of neighbourhoods in settlement.

Initially, a total of 52 settlements were identified and divided into four clusters. The clusters were analysed by the number of settlements units and the number of neighbourhoods containing housing units. Within each category 10 points were identified totalling 60 points each given an identification number. The selection procedure is effective in translating a sample of households into a sample of the adult population. Fully experienced interviewers were employed and given detailed sampling 


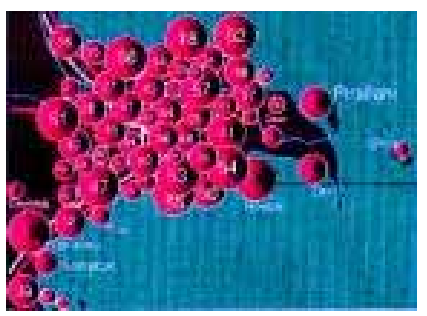

1. The Big Baku area in the territory of Azerbaijan
Density \& Land value

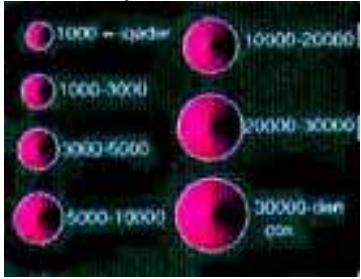

2. Parameters

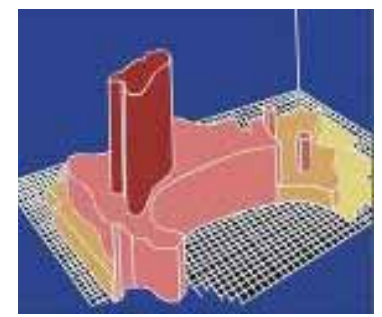

3. Capital Baku and other settlements in the Big Baku area

Figure 2: Analysis of density accommodation for settlements and the population in the Big Baku area.

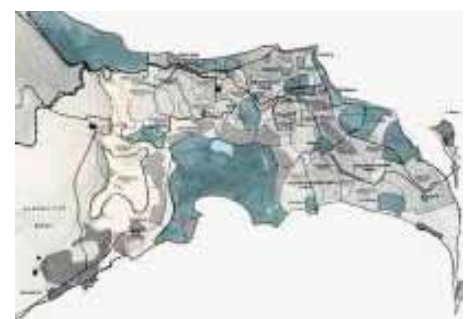

1. Environment and Cluster's Location

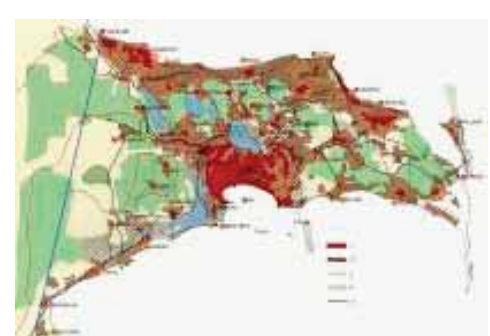

2. Settlements Location and Residential Mobility

Figure 3: Methodology of urban sustainable development research for regional planning.

instructions in order to insure correct understanding and execution of the different procedures to follow prior to visiting selected households. The analysis was spent on following questions: (1) settlement history and evolution, (2) public services and transportation, (3) cultural heritage and architecture, (4) school and kindergarten, (5) parks and recreation, (6) shopping and entertainment, (7) community participation and involvement, (8) neighbourhood and attributes of neighbouring, (9) settlement and residential mobility, (10) safety, (11) employment and journey to work, (12) environment, (13) health and health-care facilities, (14) other domain satisfactions, (15) regional issues, (16) demographics (Fig. 3).

\section{FINDINGS ABOUT THE SETTLEMENT ENVIRONMENT AND URBAN LIFE IN THE BIG BAKU AREA}

Conceptually, urban life implies the 'places' where people carry out their daily lives, most of which occur within the settlement environment [6]. In the Big Baku area study, the settlement environment was considered at three levels: the individual home or dwelling, the micro neighbourhood within which the dwelling was located, and the macro neighbourhood. Consideration was also given to attributes of each of these place domains. For instance, questions about environmental attributes (traffic, noise, upkeep), social attributes (family, friends, safety), and public service attributes (schools, parks, transportation, police protection) were asked about the respondent's micro neighbourhoods [7]. At the macro neighbourhood level, consideration was given to shopping, accessibility 
and transportation, and recreation while people's assessments of housing costs, space and size of property were considered for the individual dwelling. At each level, respondents were asked to evaluate several attributes and then give a summary satisfaction score to a single question. Using the same 7-point response categories, they were asked to express their overall satisfaction with their dwelling, their micro neighbourhood, and their macro neighbourhood. Table 1 presents the overall satisfaction scores for settlement, micro neighbourhood and macro neighbourhood for the entire sample, for Big Baku residents.

Macro neighbourhood quality is shown in Fig. 4. This index was subsequently used in modelling determinants of macro neighbourhood satisfaction.

The average value was 4.3 out of 7 where seven represents the most satisfactory situation. In assessing micro neighbourhood attributes as defined as respondent's immediate surroundings that are visible from the vicinity of their home, issues related to physical environment, such as high levels of noise, overcrowding and heavy traffic were considered. Respondents were read a list of problems that exist in some neighbourhoods in Big Baku and asked to indicate whether they thought they were (1) a big problem in this neighbourhood, (2) somewhat of a problem or (3) not a problem at all. In terms of the most pressing physical neighbourhood problems, concerns over supply of water and the water drain are the highest with $64 \%$ of all respondents feeling that this was a problem.

Finally, social networks within the neighbourhood were measured by asking about the number of nearby friends and families and attributes of neighbouring. Responses were combined into Neighbouring Index (Fig. 5). Attributes of neighbouring included the number of neighbours known by name, the

Table 1: Settlement, Neighbourhood, Community Mean Satisfaction Scores for Big Baku.

\begin{tabular}{lccc}
\hline & \multicolumn{3}{c}{ Big Baku } \\
\cline { 2 - 4 } Domain & Baku & East side & West side \\
\hline Settlement/Dwelling & 5.20 & 5.25 & 5.35 \\
Micro Neighbourhood & 4.91 & 4.72 & 5.12 \\
Macro Neighbourhood & 4.75 & 4.70 & 4.94 \\
Number of Respondents & 817 & 428 & 389 \\
\hline
\end{tabular}

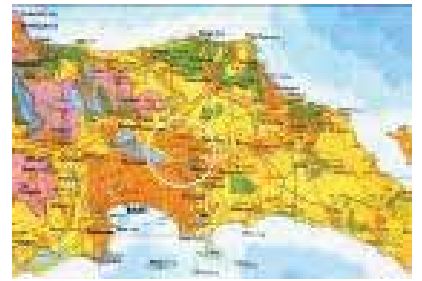

1. The typological groups of Apsheron settlements

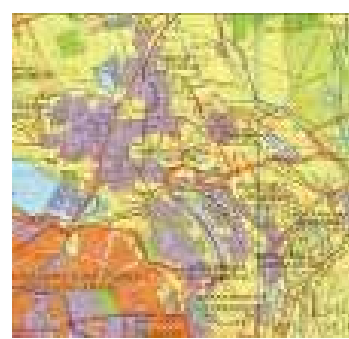

2. Near to Baku capital city (Sabunchi)

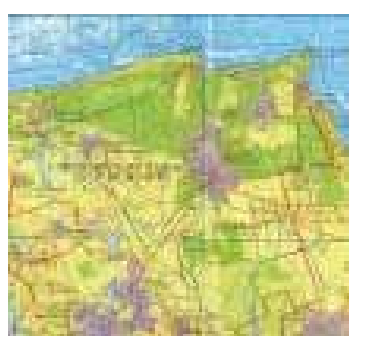

3. Capital Baku and other settlements in the Big Baku area

Figure 4: Macro Neighbourhood Quality Index. (1) Definition of settlements typological features in Big Baku (2) near to Baku capital city, (3) near Caspian Sea. 


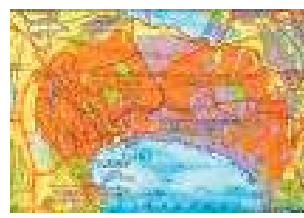

Baku city

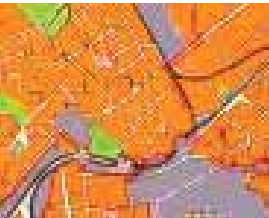

Montino

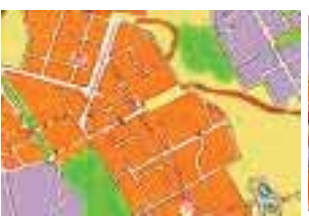

$8 \mathrm{~km}$ BEDY

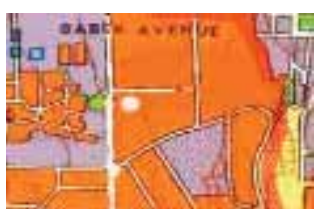

Akhmedli

Figure 5: Definition of settlements typological features in Baku located (1) in Pre-war period (1920-40), (2) in Post-war period (1945-60), (3) in Late Soviet period (1970-90).

frequency of visiting and exchanging favours with neighbours. Residents tended to have more family living nearby. The average value was 2.9 out of 5 where five represents the highest neighbouring score.

The most common indicators were then merged to create a Participation Index in order to measure the overall levels of community involvement. Respondents who answered all questions positively were designated as activists. Conversely, those responding negatively to all four questions were categorised as disengaged. The higher the index score, the greater the level of engagement. Overall $59 \%$ of respondents were disengaged. As a way of examining prospects about the future of the region, two sets of questions were asked: one dealt with moving intensions and the other dealt with people's expectations about the QoL in Baku in 10 years. With respect to moving intentions, only $25 \%$ of the people wanted to move from their current residence and $27 \%$ said they would 'definitely move' or 'probably move' within the next 2 years. Most of them would like to move either at the same area (45\%) or another neighbourhood in Big Baku (50\%). Only a small proportion of residents $(10 \%)$ would like to move elsewhere in Azerbaijan. City of Baku has been continued to attract the people.

On average, survey respondents were more optimistic than pessimistic about the region's future. Those who thought the QoL in city would improve in the coming decade were 52\%. Nonetheless, about $20 \%$ believed the QoL would deteriorate over the decade while $21 \%$ said there would be no change in regional QoL. Residents were the more hopeful; optimists for the neighbourhood, that is, those who thought the QoL in neighbourhood would improve in the coming decade were 64\% [8]. The question related desirable environment was asked to respondent was reported that they will move from their dwelling in next to two years. Respondents who preferred to live in the environment that has effective public transportation, availability of shopping facilities, parks, schools within 10-15 minutes of walking time, accessible to other places in 20 minutes by car, five- to six-storey apartment blocks, and relatively less urban open spaces were $41 \%$; respondents who preferred the environment that has dependency to car, weak public transportation, accessible to other places in 45 minutes by car, single family houses with gardens were $47.5 \%$ and respondents who prefer to live in the environment that has dependency to car, weak public transportation, availability of shopping facilities, parks, schools within 10-15 minutes of walking time, accessible to other places within 45 minutes by car, high-rise apartment blocks and lots of urban green areas are $10 \%$.

Findings about the settlement environment and urban life in the Big Baku area have been used by drawing up of the Urban Sustainable Development Model (USDM).

\section{USDM FOR REGIONAL PLANNING PROCESS}

The study proposed USDM composed of analysis-synthesis-simulation-evaluation stages. Although the findings about the settlement environment and urban life in the Big Baku area is applied in the evaluation stage, it is essential to define the analysis and synthesis stages and illustrate their link too 
effectively and efficiently to conduct a revitalisation process. Moreover, each stage has also its internal feedback loops: elicitation, definition, structuring and maintenance. The categorisation of these loops is based on Ozkaya and Akin's [9] definitions done for the requirements in regional planning process. Successfully defining the requirements of an urban environment is significant to underline the multi-criteria process of settlement requalifying the existing environments before revitalisation works are defined.

Each feedback loop links the evaluation methods with the requirements of its associated stage. Instead of relying heavily on technical solutions by professionals, each loop suggests to conduct both quantitative and qualitative approaches. These loops and stages are important in terms of correlating user aspects into the evaluation of regional planning features and defining a comprehensive programme of sustainable development (Fig. 6).

Thus, this proposed model allows stepwise handling of dealing with user needs for the revitalisation. It aims to reconsider the economic, functional and physical lifespan and sustainability of settlements in relation to the diversity of meanings.

\subsection{Elicitation}

Elicitation loop refers to engagement with requirement elicitation activities to understand the capacities, expectations and desires of diverse settlements to create sustainability between them and revitalisation process from the early stages. During this loop, the study proposes using interviewing, brainstorming and storyboarding methods in order to gain a better understanding of the functional and physical performance of urban environments in relation to diverse settlement needs, capabilities and expectations. Empirical methods, such as focus groups, user workshops, think-aloud protocols, incident diaries, field observations, can also assist in better clarifying the meaning of each built environment and uncover more problems regarding those environments through active participation of neighbourhood.

\subsubsection{Definition}

The economic, functional and physical lifespan of settlements should be reconsidered in relation to the needs of urban sustainable development. Urban environment definition is exploration of city components (dwelling, centre, park, transport etc.) by assigning feature attributes such as priority,

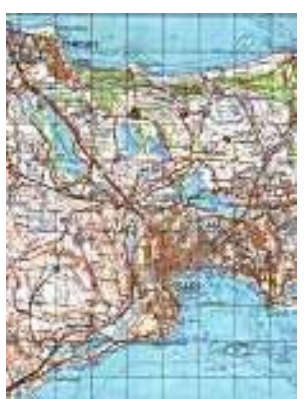

1. Situational plan of the settlement environment

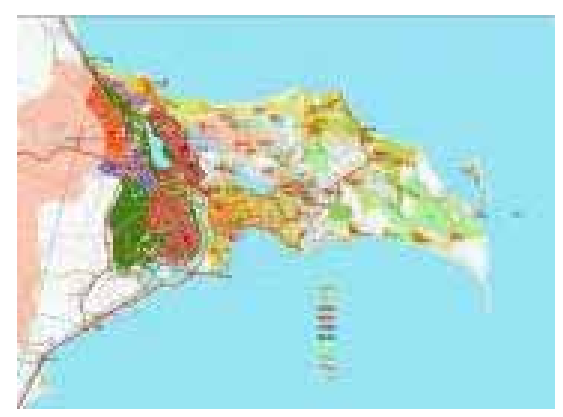

2. Directional choice of a urban sustainable development for regional planning in the Big Baku area

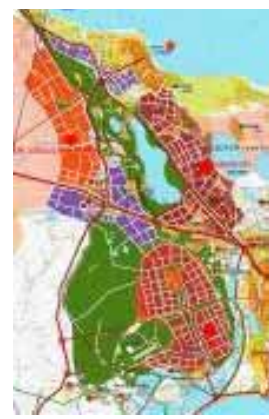

3. Planning structure of preferable development

Figure 6: Use of the USDM for regional planning process. 
risk, effort, cost, time with respect to the universal regional planning principles. The settlement needs that are obtained from the above-mentioned elicitation techniques are now documented and systematised into the settlement revitalisation attributes by using the most well-known requirements prioritisation techniques, such as playing game [10] and/or pairwise comparison [11, 12].

\subsubsection{Structuring}

Structuring loop is the most important loop during the synthesis stage where planners move from the problem space to the solution space of urban sustainable development. They focus on generating alternative solutions regarding the defined user needs in terms of revitalisation. Existing regional planning solutions and use cases play an essential role while stimulating creative revitalisation alternatives. Moreover, planners can also make use of non-empirical usability methods combined with regional planning criteria, such as task analysis, property checklists, expert appraisal, and cognitive walkthroughs that can guide planners to successfully revitalise and prescribe potential solutions to the problems of urban sustainable development.

\subsubsection{Maintenance}

This loop is a natural outcome of the previous three loops. Since different groups of the population experience the urban environments in many different ways, this loop becomes essential to underline the multi-actor process during the requalification of settlements. Maintenance promotes traceability (switching back and forth between user needs and regional planning requirements) and binds specified regional planning features of the created urban sustainable development alternatives through verification and validation within real field- and/or 2D-3D CAD environment.

\section{CONCLUSION}

This paper has presented an overview of a study designed to provide systematic data covering the urban sustainable development for settlements in Big Baku. The primary source of information was a city survey. The study was intended to inform policy makers and planners on conditions in the region at the beginning of the 21 st century and establish a benchmark for measuring social and environmental changes that were expected to occur in the decades to come. At the same time, it aimed at improving our understanding of relationships between perceptions, evaluations and behaviours and the urban conditions to which people were responding. Research into settlements and neighbouring through the urban sustainable development and the QoL provides a unique opportunity to measure community and neighbourhood satisfaction through evidence-based research to 'make the difference' to people's QoL by informing future settlements and urban sustainable development policy in Big Baku and encouraging framework conducive to citizen involvement. The research on the urban environment foresees that the quality of the urban environment and settlements are among the basic indicators of the urban sustainable development in any community. Urban environment not only provides space for shelter but is also responsible for healthy family life, care of children and personal fulfilment. Therefore, it was important for the strategic regional plan of Big Baku to analyse the existing problems of the settlement areas in the metropolitan area of Big Baku. The information collated in this research could be helpful to determine developed strategies for urban sustainable development in Big Baku. First of all, measuring QoL could help to determine most critical neighbourhoods as a result of their physical and social conditions. While developing policies, decision-makers should consider the need for the revitalisation of neighbourhoods in terms of improving social, recreational, educational and infrastructural services [13]. In general, the west side of the Apsheron peninsula was found to be less satisfactory in terms of resident evaluation. According to the results of the survey, unplanned areas located between Alaty and Garadag in the west side 
were evaluated negatively by the residents. Since community engagement level was considered low in general, there is a need to study on community engagement to raise the community participation in Big Baku. This approach has special importance for the regional planning of the urban sustainable development process [14].

The increasing globalisation and specialisation in the current regional planning and the urban sustainable development requires an interdisciplinary approach to the urban sustainable development and revitalisation methods for the construction of new or existing urban environments [15]. In this respect, the main issue in this paper is proposing a systematic methodology to requalify the current urban environments and assist planners during the planning to produce the sustainable development alternatives that can be better suited to the expectations of diverse settlements with different ages, abilities and sizes. Thus, an USDM is proposed that can be effectively used in analysing, synthesising, simulating and evaluating current settlement environments with the aim of integrating urban sustainable development and regional planning principles. In the model, the planning was engaged with qualitative and quantitative techniques throughout the four loops as they iterate towards the final renovation design. This model can also be a response to regional planning community whose planning are failing to gain universal acceptance and approval because of the insufficient requirement integration of diverse population groups into the urban sustainable development process. This model can guide planners to develop innovative regional planning solutions that maximise city functionality, affordability, attractiveness, safety, effectiveness, efficiency and satisfaction. This study highlights the importance of USDM from two points of view: (1) importance of a systematic evaluation approach to effectively deal with the challenge of requalifying the existing environments and (2) the planner's key role during the revitalisation process in the proposed model, where urban sustainable development requirements are combinations obtained from different usability techniques during whole regional planning process. This systematic approach is more feasible to identify more regional planning aspects and incorporate more experiential issues into alternative solutions. So, this stepwise model allows planners and practitioners to avoid dissatisfaction and ensures the accomplishment of effective and efficient revitalisation. Thus, the study considers the USDM directed by universal planning features as the heart of settlement revitalisation practices. Moreover, since sustainable planning touches every aspect of the settlement environment, the model has to be practiced by architects, urban planners and landscape architects.

\section{REFERENCES}

[1] Huseynov, E., Sustainable development of new cities - "Ecocities" in the Regional plan of Big Baku // Works of the Georgian Technical University, 2 (476) Tbilisi, Georgia, pp. 88-91, 2010.

[2] Huseynov, E. Concept for sustainable development of a new Silk way cities // Great Silk Way. Eurasiya cultures dialogue. International Scientific Conference, Baku, pp. 92-103, 2003.

[3] Aliyev, A. Planning of new cities and satellites cities in Apsheron // Urbanism, Jurnal: No. 9, Society of Urbanists of Azerbaijan, Baku: МБM, pp. 55-59, 2006.

[4] SELMA Spatial De-concentration of Economic Land Use and Quality of Life in European Metropolitan Areas. Deliverable D02 WP2 Quality Life Indicators, SELMA, 2004.

[5] Gregory, D., Johnston, R., Pratt, G., et al. (eds), "Quality of Life". Dictionary of Human Geography, 5th edn., 2009.

[6] Carmona, M., et al., Public Places- Urban Spaces, Architectural Press: Oxford, 2003.

[7] Barton, H. et al., Shaping Neighbourhoods, Spon Press: London, 2003.

[8] Aliyev, A., About tipology of city settlements in Apsheron // Urbanism, Jurnal: No. 10. Society of Urbanists of Azerbaijan, Baku, Мемar (Architecture), pp. 50-54, 2007. 
[9] Ozkaya, I. \& Akin, O., Electronic requirement management: A framework for architectural requirement engineering // Proceedings of the 9th Europian International Conference: E-activities and Intelligent Support in Design and the Built Environment, pp. 173-185, 2003.

[10] Beck, K., Extreme Programming Explained. Addison-Wesley: Reading MA, 1999.

[11] Moughtin, I.C. et al., Urban Design: Method and Techniques, Architectural Press: Oxford, 2003.

[12] Saaty, L. \& Vergas, G., Models, Methods, Concepts and Applications of the Analytic Hierarchy Process. Kluwer: Norwell, 2001.

[13] Huseynov, E., Historical heritage and urban renovation in modern conditions // The historical architectural heritage in the new social political situation / International Preparatory Conference. February 20th-22nd, Florence, Italy, pp. 106-111, 2007.

[14] Huseynov, E., Planning for a sustainable development of Azerbaijan Republic cities // International Academiya of East Country Architecture, Azerbaijan National Scientific Akademiya, Chapter 5, Architecture, Baku, pp. 99-109, 2010.

[15] United Nations Environmental Programme, Global Environmental Outlook 3, Earthscan Publications: London, 2002. 